\title{
Tensile fatigue behaviour of Ultra-High Performance Fibre Reinforced Concrete combined with steel rebars (R-UHPFRC)
}

\author{
Tohru Makita*, Eugen Brühwiler \\ Laboratory of Maintenance and Safety of Structures (MCS), École Polytechnique Fédérale de Lausanne (EPFL), Station 18, 1015 Lausanne, Switzerland
}

\section{A R T I C L E I N F O}

Article history:

Received 23 May 2013

Received in revised form 7 September 2013

Accepted 10 September 2013

Available online $\mathrm{xxxx}$

\section{Keywords:}

UHPFRC with steel rebars

Tensile fatigue

Fatigue endurance limit

Stress transfer

Fatigue deformation behaviour

\begin{abstract}
A B S T R A C T
Ultra-High Performance Fibre Reinforced Concrete (UHPFRC) combined with steel rebars, subsequently called R-UHPFRC, is a promising building material implying a novel technology for the improvement of concrete structures. Steel rebars enhance effectively the resistance of UHPFRC while reducing variability in the tensile behaviour of monolithic UHPFRC due to variation in fibre distribution and orientation. When a thin layer of R-UHPFRC is overlaid on top of a concrete bridge deck slab, it is subjected to repeating wheel loads and fatigue limit state needs to be considered. This paper presents the results of tensile fatigue tests on R-UHPFRC elements for the determination of its fatigue behaviour. Experimental results show a fatigue endurance limit at 10 million cycles at a solicitation level of $S=0.54$ for $S$ being the ratio between the maximum fatigue force and the ultimate strength. Over the fatigue life of the specimens, stress was transferred from UHPFRC to steel rebars. Fatigue resistance of R-UHPFRC shows that it has a significant potential for fatigue strengthening of reinforced concrete structural elements like bridge deck slabs.
\end{abstract}

(c) 2013 Elsevier Ltd. All rights reserved.

\section{Introduction}

Ultra-High Performance Fibre Reinforced Concrete (UHPFRC) is a cementitious composite material, generally consisting of cement, quartz sand, silica fume and fibres. It has eminent properties: relatively high compressive strength $(\geqslant 180 \mathrm{MPa})$ and tensile strength $(\geqslant 10 \mathrm{MPa})$, strain-hardening behaviour under tensile stress (given a certain volume of fibres) and very low permeability because of an optimised dense matrix. These properties make UHPFRC suitable for "hardening" those parts of structural members that are subjected to mechanically and environmentally severe actions. Since the tensile behaviour of UHPFRC depends on fibre orientation and distribution [1], it is proposed that steel rebars are arranged in UHPFRC, subsequently called R-UHPFRC, to provide a significant increase in resistance and improvement of structural behaviour for UHPFRC. Also, variation in tensile behaviour of UHPFRC due to fibre orientation and distribution is reduced when steel rebars are added.

In recent years, the necessity to improve the load bearing capacity of bridges is growing due to the increase of traffic loads for more efficient transport of industrial products. Strengthening of concrete bridge deck slabs is often conducted by adding a layer

\footnotetext{
* Corresponding author. Present address: Environment/Engineering Department Central Nippon Expressway Company Limited (NEXCO-Central), 2-18-19 Nishiki, Naka-ku, Nagoya 460-0003, Japan. Tel.: +81 52222 3623; fax: +81 522223576 .

E-mail addresses: t.makita.ab@c-nexco.co.jp, tohru.makita@epfl.ch (T. Makita), eugen.bruehwiler@epfl.ch (E. Brühwiler).
}

of reinforced concrete (RC) on top of the slab. However, thickness of the RC layer sometimes becomes so large for fulfilling structural safety requirements that it is necessary to increase the load bearing capacities of other structural members to support the increased self-weight due to the massive additional RC layer. Application of relatively thin R-UHPFRC overlays instead of RC layer leads to no or only minor increase of self-weight since usually cover concrete of the existing elements needs to be removed. Besides, dense matrix of UHPFRC provides waterproofing properties which in addition allows efficient use of the UHPFRC technology [2].

Although the static behaviour of R-UHPFRC has been investigated by some researchers ([3-6]), few research results have been reported so far in the literature on the fatigue behaviour of $\mathrm{R}$ UHPFRC. Four-point bending fatigue tests were conducted on beams made of Compact Reinforced Composite (CRC), an UHPFRC combined with high percentage of steel rebars (5-20\%) [7]. After determining ultimate static strength of the beam to be $39.77 \mathrm{kN}$, three levels of maximum fatigue force, i.e. $42 \%, 70 \%$ and $86 \%$ of static yield strength $(=38 \mathrm{kN})$, were determined while minimum fatigue force was always $0 \mathrm{kN}$. Each combination of the fatigue force had one specimen. Specimens subjected to $70 \%$ and $86 \%$ of static yield strength failed at 403790 and 52430 cycles respectively, whereas the specimen subjected to $42 \%$ of static yield strength sustained 5305150 cycles and was regarded as reaching run-out. It is concluded that very few cracks were observed on the specimens until failure or end of the test and the matrix did not lose the ability to transfer fatigue force because applied maximum fatigue force remained constant in displacement controlled mode. 


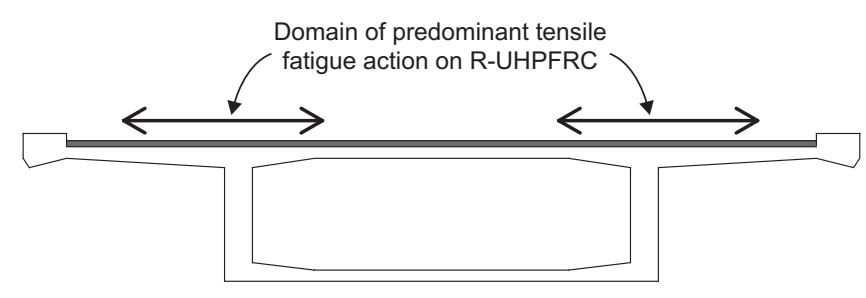

Fig. 1. Bridge deck slab strengthened with R-UHPFRC layer.

This literature review reveals that uniaxial tensile fatigue testing of R-UHPFRC has not been performed so far and knowledge of tensile fatigue behaviour of R-UHPFRC is scarce. There are several papers about the fatigue behaviour of UHPFRC ([8-12]) and steel rebar respectively ([13-15]). To some extent the fatigue behaviour of R-UHPFRC might be understood as a simple superposition of the fatigue behaviour of UHPFRC and steel rebar. However, since both UHPFRC and steel rebars carry tensile stress and stress distribution is supposed to occur between the two materials, it is necessary to investigate the fatigue behaviour of R-UHPFRC structural members.

The objectives of the present paper are to describe the tensile fatigue behaviour of R-UHPFRC and to investigate the effective function of steel rebars. Uniaxial tensile fatigue tests were chosen approximately reproducing the situation of an R-UHPFRC overlay on top of bridge deck slabs, including tensile fatigue stresses in the cantilever parts (Fig. 1). Experimental tests are detailed and results are analysed.

\section{Experimental campaign}

\subsection{Specimens, instrumentation and test set-up}

The mix of UHPFRC is characterised by 3.0 vol.\% content of $13 \mathrm{~mm}$ long steel fibres with a diameter of $0.16 \mathrm{~mm}$ and by the use of CEM III/B type cement which contains a high percentage of blast furnace slag (66-80\%) (Table 1). Three prisms with a section of $40 \mathrm{~mm} \times 40 \mathrm{~mm}$ and a length of $160 \mathrm{~mm}$ were cast with the same UHPFRC as used for the fabrication of R-UHPFRC specimens, and tested 56 days after casting. Average compressive strength and modulus of elasticity were $217 \mathrm{MPa}$ and $47 \mathrm{GPa}$ respectively. Steel rebars arranged in the UHPFRC were of B500B grade with a nominal yielding strength of $500 \mathrm{MPa}$.

The specimen is $750 \mathrm{~mm}$-long and $40 \mathrm{~mm}$-thick with varying width ('dog-bone shaped' specimen) to force fracture to occur within the $250 \mathrm{~mm}$-long tapered central part of the specimen. The width of the central and end parts of the specimen were $110 \mathrm{~mm}$ and $150 \mathrm{~mm}$ respectively, and there were $45 \mathrm{~mm}$-long transitional zones between the central and end part (Fig. 2).

The fabrication procedure of the specimen was as follows. First, three steel rebars of $8 \mathrm{~mm}$ diameter with a spacing of $40 \mathrm{~mm}$ were arranged in the wooden forms. Rectangle shaped specimens with $150 \mathrm{~mm}$-width were cast and demoulded 7 days after casting, and then kept in the testing hall at constant climatic condition for more than 312 days. Aluminium plates $(250 \mathrm{~mm}$ long, $150 \mathrm{~mm}$ wide and $2 \mathrm{~mm}$ thick) were then glued using epoxy resin to both surfaces of the specimen end parts as strengthening elements. By using a water jet cutter, the rectangle shaped specimens were cut into the dog-bone shape.

Two $250 \mathrm{~mm}$-long Linear Variable Differential Transducers (LVDTs) and five displacement transducers with a $50 \mathrm{~mm}$ measurement length were used to measure the specimen deformation (Fig. 2). LVDTs were glued to both specimen sides such as to capture global specimen deformation. In the present paper the average of deformation as measured by the two LVDTs are always referred to as global deformation. The five displacement transducers were set up on the specimen surface to measure local specimen deformation in five consecutive zones. Force was measured by the load cell installed in the actuator of the $1000 \mathrm{kN}$ servo-hydraulic testing machine.

\subsection{Testing program}

A single quasi-static tensile test was first performed to understand the behaviour of the R-UHPFRC under quasi-static tensile force using the same specimen as for the fatigue test.

Then, a fatigue test program was established with the objective to explore the fatigue endurance limit of R-UHPFRC. Fatigue force was determined with reference to stress range of steel rebars because the fatigue behaviour of R-UHPFRC was assumed to depend on the fatigue behaviour of steel rebars.

It was found in [16] that although the constant amplitude fatigue endurance limit of straight steel rebars at 2 million cycles was $170 \mathrm{MPa}$ according to design codes, RC slab-like beams sustained more than 10 million fatigue cycles with stress range of about $230 \mathrm{MPa}$ in steel rebars. In view of these findings, maximum fatigue force was chosen to cause stress range between $170 \mathrm{MPa}$ and $230 \mathrm{MPa}$ in steel rebars, while minimum fatigue force was always $10 \%$ of maximum fatigue force.

Testing procedure was as follows: first, the specimen was subjected to quasi-static tensile force until the average reading of the two LVDTs reached the target deformation (corresponding to strains between $1.0 \%$ and $1.5 \%$ ) and then unloaded. The force corresponding to the target deformation was adopted as maximum force level for the fatigue test. Because of the variation of elastic limit strength of UHPFRC (which is likely due to local variations of fibre distribution and orientation [1]), deformation (instead of force) provides more reliable information on the tensile behaviour of R-UHPFRC. Consequently, fatigue tests were conducted under force control at constant amplitude in a servo-hydraulic machine at a frequency of $10 \mathrm{~Hz}$.

Deformation and force data were recorded with a frequency of $200 \mathrm{~Hz}$. The initial and final phases of the test were permanently recorded, while between these phases data was recorded for $1 \mathrm{~s}$ every 600 cycles.

When a specimen sustained 10 million cycles, this result was regarded as 'run-out', and the test subsequently was continued at an increased maximum tensile fatigue force.

Table 1

Composition of UHPFRC mix.

\begin{tabular}{|c|c|c|c|}
\hline Component & Type & Mass $\left(\mathrm{kg} / \mathrm{m}^{3}\right)$ & Remarks \\
\hline Cement & CEM III/B & 1277.4 & \\
\hline Silica fume & Elkem microsilica $971 \mathrm{U}$ & 95.8 & $7.5 \%$ of cement mass \\
\hline Sand & Quartz sand MN 30 & 664.6 & $d_{\max }<0.5 \mathrm{~mm}$ \\
\hline Steel fibres & Bekaert OL 13/0.16 mm & 235.5 & 3.0 vol. $\%$, brass coating \\
\hline Superplasticiser & Sikament P5 & 42.3 & $3.3 \%$ of cement mass \\
\hline Water & & 198 & $W / C=0.155$ \\
\hline
\end{tabular}



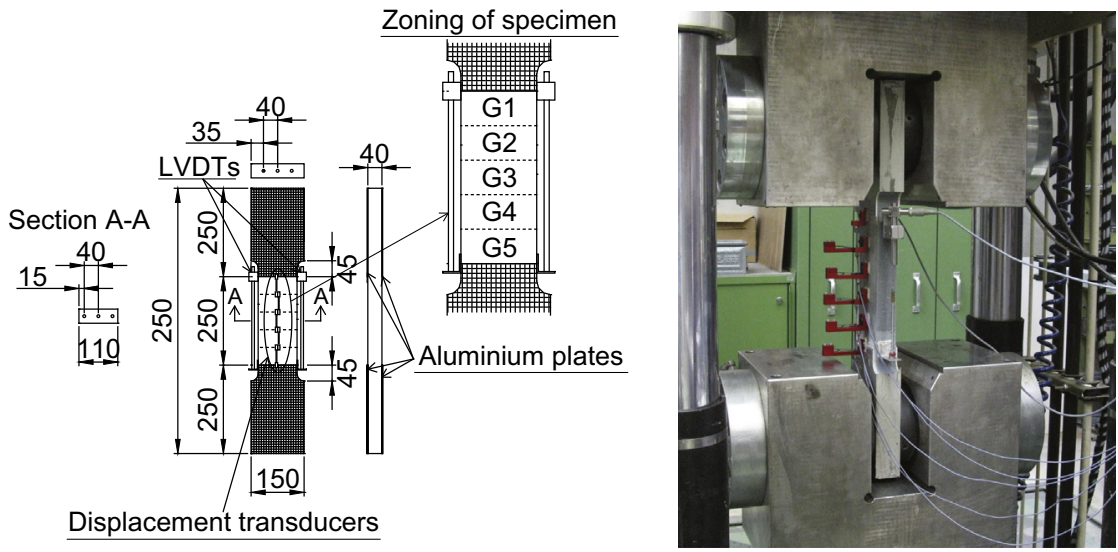

Fig. 2. Specimen geometry, measuring devices and test set-up.

In the present paper, the fatigue endurance limit is defined as the force level below which no fatigue failure occurs up to $10 \mathrm{mil}-$ lion cycles. With respect to bridge deck slabs, 10 million extreme force cycles are considered to be realistic to occur during the service life for heavily trafficked bridges. Also, limited available time for the experimental campaign imposed a maximum number of 10 million cycles which is usually considered as a lower bound of the very high cycle fatigue domain [17].

\section{Results of experimental tests}

\subsection{Quasi-static tensile behaviour of R-UHPFRC}

The tensile behaviour of R-UHPFRC is explained by analysing the force-global deformation curve obtained from a single quasistatic tensile test (Fig. 3). Letters in brackets (A-G) in the curve show characteristic points, by referring to which the tensile behaviour of R-UHPFRC is described:

- The elastic domain (point (A-B)) is governed by the behaviour of UHPFRC until reaching the force corresponding to the elastic limit strength of UHPFRC $F_{e}$ (called 'elastic limit strength of RUHPFRC' hereafter). Invisible microcracking in UHPFRC matrix starts at this force level.

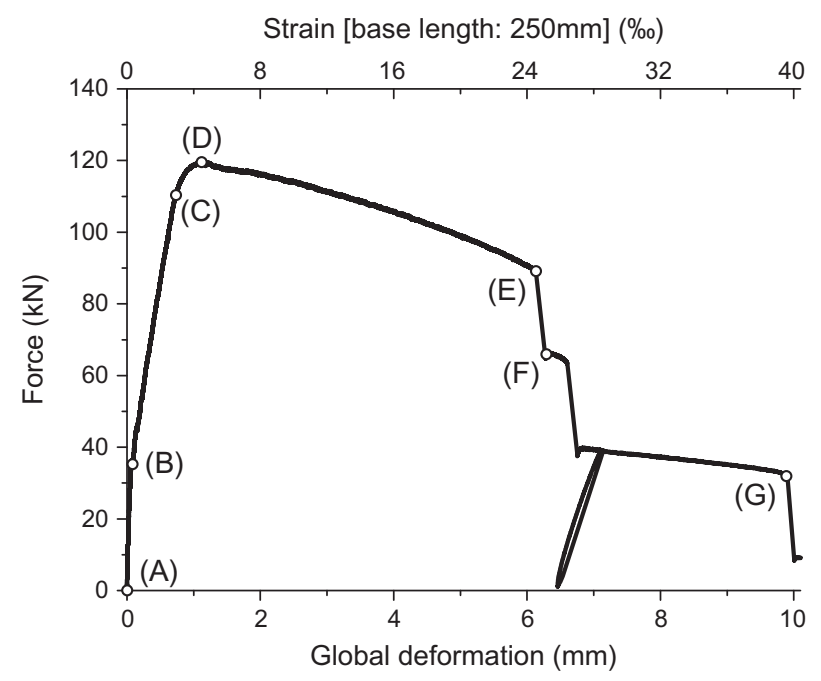

Fig. 3. Force-global deformation relation of R-UHPFRC obtained from a quasi-static tensile test.
- These microcracks are bridged and controlled by fibres. After UHPFRC enters into the strain-hardening domain beyond point (B), more microcracks develop in the UHPFRC volume. Although UHPFRC reduces its modulus of deformation (the ratio of stress to strain) considerably, there is no significant decrease of RUHPFRC stiffness due to the steel rebars which are still in the elastic domain. High bond strength between UHPFRC and steel rebars enables the perfect composite behaviour of R-UHPFRC [6].

- Steel rebars start to yield at point (C). The domain between point (C) and (D) is the transition from elastic to plastic behaviour of steel rebars. When steel rebars become fully plastic at point (D), a discrete macrocrack forms in the weakest section of UHPFRC and R-UHPFRC enters into the softening domain. This macrocrack then becomes visible.

- Steel rebars fracture one by one. Three steel rebars are arranged in the specimens, and the first, second and third fracture of steel rebars occurs at point $(E),(F)$ and $(G)$ respectively. Beyond $(G)$, force is carried by UHPFRC and finally the specimen fractures completely in two parts at the end of UHPFRC softening.

The tensile behaviour of R-UHPFRC may be described by the linear superposition of the tensile behaviour of UHPFRC and steel rebars [6]. From this it follows that the ultimate strength of RUHPFRC $F_{u}$ attained at point (D) $(120.0 \mathrm{kN})$ is decomposed into two units of force carried by UHPFRC and steel rebars respectively, and considering nominal yield stress in steel rebars at point (D) being $f_{s y}=500 \mathrm{MPa}$ (B500B grade steel), the ultimate strength of UHPFRC $\sigma_{U u}$ as obtained from this test is calculated as:

$\sigma_{U u}=\frac{F_{u}-A_{s} \cdot f_{s y}}{A_{U}}=\frac{120 \cdot 1000-\pi \cdot 4^{2} \cdot 3 \cdot 500}{110 \cdot 40-\pi \cdot 4^{2} \cdot 3} \approx 10.5 \mathrm{MPa}$

where $A_{s}$ is the sectional area of three steel rebars; $A_{U}$ the sectional area of UHPFRC.

\subsection{Results of tensile fatigue tests}

Table 2 summarises the results of tensile fatigue tests on $12 \mathrm{R}$ UHPFRC specimens. A specimen was regarded as failed when the global deformation reading reached $2.5 \mathrm{~mm}$, corresponding to strain of $10 \%$.

Fig. 4 shows the $S-N$ diagram with the results obtained in the present study. In order to eliminate variations in material composition, specimen size and test set-up, normalized force $S$ is used for the axis of ordinate. The ratio of maximum fatigue force $F_{\max }$ to the ultimate strength of each specimen $F_{u, i}$ was used as fatigue solicitation indicator $S$ where $F_{u, i}$ was estimated based on the result of 
Table 2

Results of tensile fatigue tests of R-UHPFRC.

\begin{tabular}{|c|c|c|c|c|c|c|}
\hline Test no. & $F_{\max }{ }^{\mathrm{a}}(\mathrm{kN})$ & & $F_{u, i}{ }^{\mathrm{b}}(\mathrm{kN})$ & $F_{\max } / F_{u, i}$ & $N^{\mathrm{c}}\left(10^{6}\right)$ & Remarks \\
\hline \multirow[t]{2}{*}{1} & $\mathrm{i}$ & 60.9 & 131.3 & 0.46 & 10.00 & run-out \\
\hline & ii & 80.9 & & 0.62 & 0.09 & \\
\hline \multirow[t]{3}{*}{2} & i & 67.0 & 125.8 & 0.53 & 13.09 & run-out \\
\hline & ii & 72.0 & & 0.57 & 17.78 & run-out \\
\hline & iii & 77.0 & & 0.61 & 0.73 & \\
\hline \multirow[t]{2}{*}{3} & $\mathrm{i}$ & 68.9 & 132.2 & 0.52 & 10.04 & run-out \\
\hline & ii & 73.9 & & 0.56 & 7.75 & \\
\hline \multirow[t]{3}{*}{4} & $\mathrm{i}$ & 57.9 & 112.6 & 0.51 & 10.20 & run-out \\
\hline & ii & 62.9 & & 0.56 & 10.00 & run-out \\
\hline & iii & 72.9 & & 0.65 & 0.46 & \\
\hline 5 & & 69.5 & 128.6 & 0.54 & 0.96 & \\
\hline 6 & & 78.3 & 138.7 & 0.56 & 4.72 & \\
\hline 7 & & 78.6 & 128.3 & 0.61 & 1.55 & \\
\hline \multirow[t]{2}{*}{8} & $\mathrm{i}$ & 74.9 & 122.9 & 0.61 & 10.01 & run-out \\
\hline & ii & 84.9 & & 0.69 & 0.52 & \\
\hline 9 & & 86.6 & 137.6 & 0.63 & 0.41 & \\
\hline 10 & & 76.9 & 122.2 & 0.63 & 0.31 & \\
\hline 11 & & 90.5 & 125.9 & 0.72 & 0.14 & \\
\hline 12 & & 75.0 & 121.7 & 0.62 & 1.00 & \\
\hline
\end{tabular}

${ }^{\text {a }} F_{\max }$ : Applied maximum fatigue force.

b $F_{u, i}$ : Estimated ultimate strength of each specimen.

${ }^{\text {c }} N$ : Sustained number of fatigue cycles.

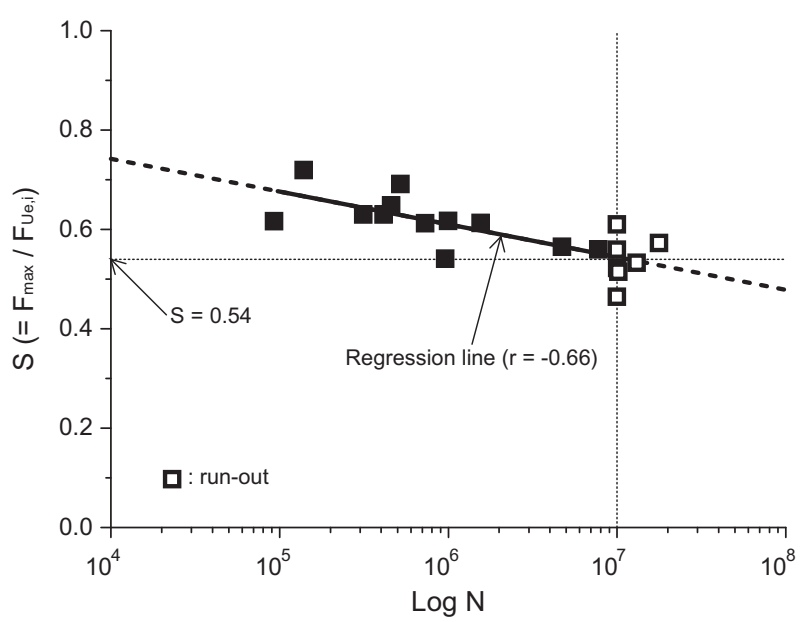

Fig. 4. $S-N$ diagram obtained from tensile fatigue tests of R-UHPFRC.

the single quasi-static tensile test of R-UHPFRC by using force-global deformation relation of each specimen obtained from quasistatic tensile preloading.

Ultimate strength $F_{u, i}$ was estimated by assuming that all specimens have the same strain corresponding to the yield and ultimate points (point (C) and (D) respectively in Figs. 3 and 5a). These strains were determined to be $2.23 \%$ and $4.58 \%$ respectively from the quasi-static tensile test (Fig. 5a). In addition, slope $a$ of a line connecting the yield and ultimate points in the forceglobal deformation relation of the quasi-static tensile test ( $Y-U$ line in Fig. 5a) was used to estimate $F_{u, i}$. In the following, the procedure to estimate the ultimate strength of each specimen is explained by using the preloading force-global deformation curve of Test 5 specimen as an example:

- As can be seen in Figs. 3 and 5a, the force-global deformation relation between point (B) and (C) is almost proportional, which is assumed to be similar for all R-UHPFRC member subjected to quasi-static tensile force. By choosing two points corresponding

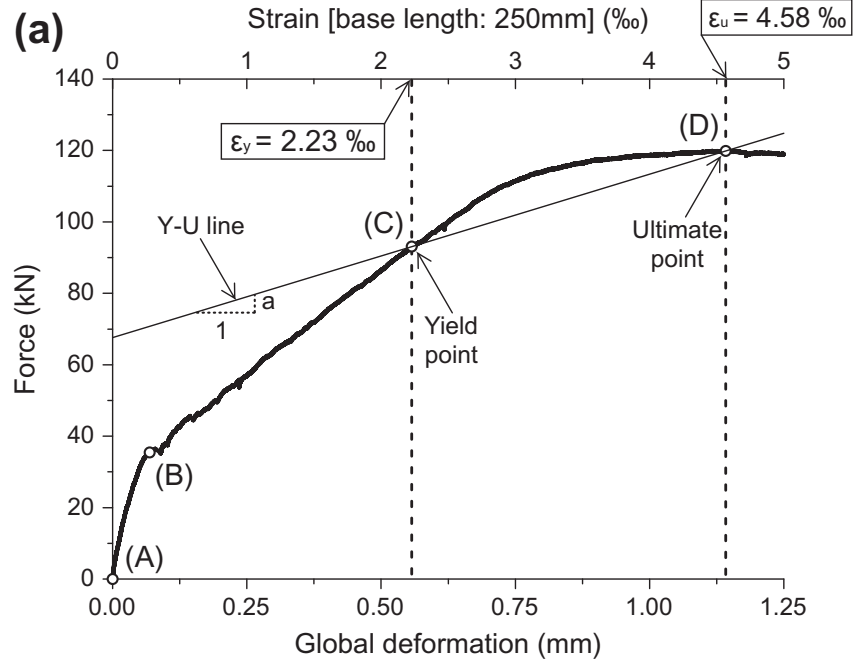

(b) Strain [base length: 250mm] (\%o)

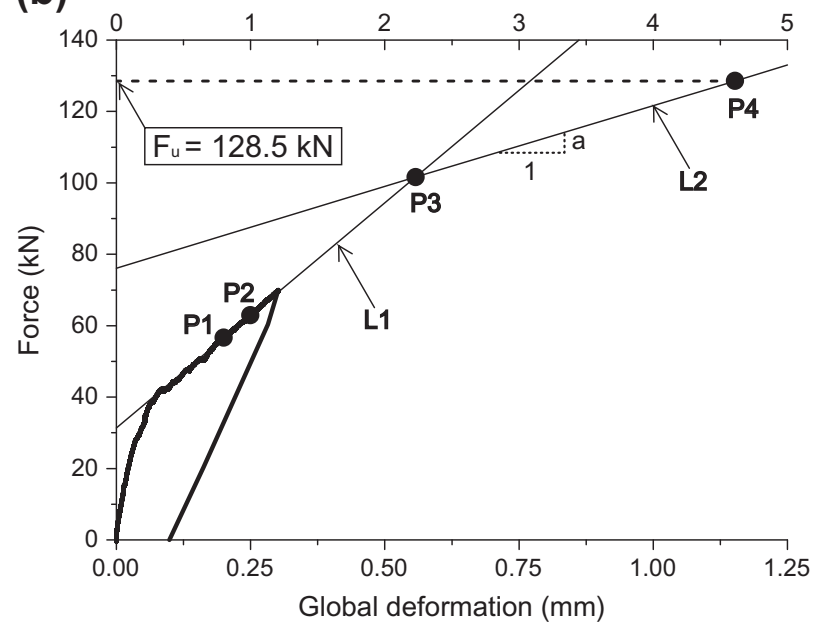

Fig. 5. (a) Force-global deformation relation of a quasi-static tensile test defining reference points and slope of a line to (b) estimate the ultimate strength of specimens using Test 5 specimen. 
to $0.8 \%$ and $1.0 \%$ strain ( $\mathrm{P} 1$ and $\mathrm{P} 2$ respectively in Fig. $5 \mathrm{~b}$ ) on the preloading force-global deformation curve, straight line L1 representing the slope of the proportional part is drawn (Fig. 5b). The strain of $0.8 \%$ was chosen because it is about $30 \%$ of the reference yield strain $2.23 \%$ while the strain of $1.0 \%$ was chosen because preloading of two specimens was stopped when global deformation readings reached $1.0 \%$ of strain.

- Then, the point corresponding to $2.23 \%$ strain on line L1 is estimated to be the yield point ( $\mathrm{P} 3$ in Fig. 5b).

- A straight line L2 with slope of $a$ passing through the yield point P3 is then drawn (Fig. 5b). The force corresponding to $4.58 \%$ strain on line L2 is determined to be the ultimate strength (P4 in Fig. 5b).

In the proposed method to estimate the ultimate strength, the chosen yield and ultimate values were adopted as reference from a single quasi-static tensile test, which might be considered as a vague assumption. However, since these stress and strain values are similar to the average values determined from three formerly conducted quasi-static tensile tests [6], the applied method is considered to provide reliable estimated ultimate strength values.

The results shown in Fig. 4 indicate a fatigue strength that may be expressed by a linear relation between $S\left(=F_{\text {max }} / F_{u, i}\right)$ and $\log N$. A straight line was determined by linear regression (without considering run-outs) with a correlation coefficient of -0.66 :

$\frac{F_{\max }}{F_{u, i}}=-0.065 \log N+1$

$S$-value at 10 million cycles is calculated to be 0.54 from Eq. (2). $S=0.54$ is also the average value of fatigue solicitation indicator $S$ of the tests that reached run-out. In addition, no specimen failed due to tensile fatigue when the maximum fatigue force was smaller than $54 \%$ of the ultimate strength. Therefore, the fatigue endurance limit at 10 million cycles may be determined to be at $S=0.54$ (indicated with a dotted line in Fig. 4). Consequently, the fatigue endurance limit of R-UHPFRC may be conservatively considered to be 50\% of the ultimate strength. Similar result, e.g. fatigue endurance limit at $50 \%$ of the ultimate strength, was obtained for RC members strengthened with R-UHPFRC (RU-RC member) [18].

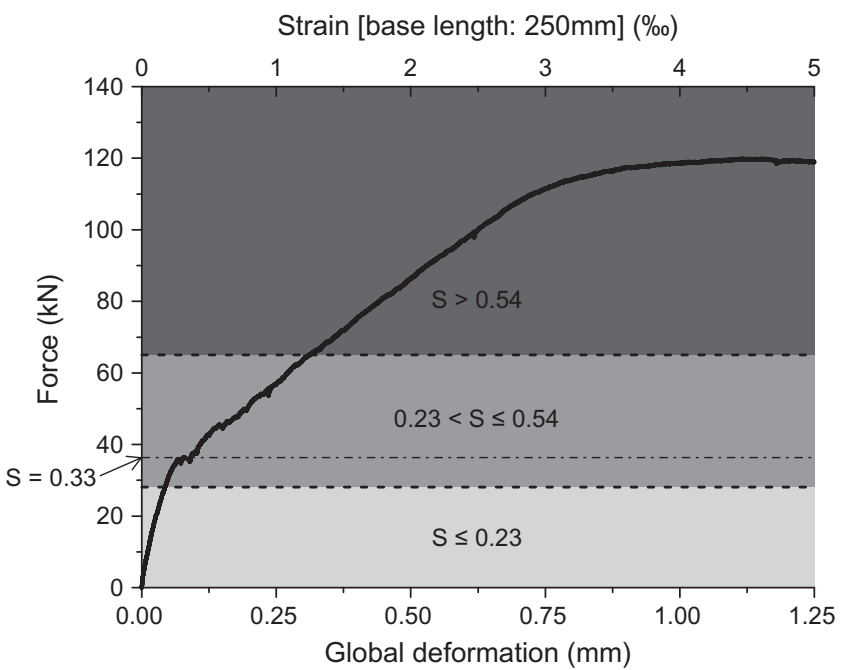

Fig. 6. Schematic representation of fatigue solicitation indicator $S$ with reference to force-global deformation relation of R-UHPFRC.
3.3. Fatigue resistance of $R$-UHPFRC as expressed by the maximum fatigue force level

The fatigue resistance of R-UHPFRC may be explained in terms of fatigue solicitation indicator $S$ which is categorised into three domains as follows (Fig. 6):

$$
\text { (1) } S \leqslant 0.23
$$

Stress in UHPFRC and steel rebars is largely below the fatigue endurance limit of both materials.

The fatigue endurance limit of monolithic UHPFRC is about $70 \%$ of the elastic limit strength [19] and average ratio of the elastic limit strength to the ultimate strength of all R-UHPFRC specimens is calculated to be 0.33 . Accordingly, $S=0.23$ is obtained as $70 \%$ of the average ratio of the elastic limit strength to the ultimate strength of R-UHPFRC. At this force level, UHPFRC contributes more significantly to the fatigue resistance of the R-UHPFRC element than the steel rebars.

\section{(2) $0.23<S \leqslant 0.54$}

Stress in the UHPFRC is beyond the fatigue endurance limit, and when $S$ is larger than 0.33 , which is the average ratio of the elastic limit strength to the ultimate strength of all R-UHPFRC specimens, the stress in UHPFRC is in the strain-hardening domain. Stress in steel rebars is still below the fatigue endurance limit.

Although monolithic UHPFRC subjected to fatigue stress at this level would fail, deformation localisation does not occur in the RUHPFRC specimen because of the stress distribution from UHPFRC to steel rebars. Contribution of UHPFRC and steel rebars to the fatigue resistance of R-UHPFRC is similar. The global deformation grows in the early stage of the fatigue test only and remains constant in the subsequent stage.

\section{(3) $S>0.54$}

Stress in the UHPFRC is in the strain-hardening domain and stress in steel rebars is higher than the fatigue endurance limit.

The fatigue resistance of R-UHPFRC is essentially determined by the steel rebars and the UHPFRC functions merely as a stress reducing element for the steel rebars. The global deformation grows in the beginning of the fatigue solicitation, and then remains constant until one of the three steel rebars fractures. Deformation localisation in UHPFRC is always at the same location as the fatigue fracture of steel rebars.

\section{Tensile fatigue behaviour of R-UHPFRC}

\subsection{Stress transfer from UHPFRC to steel rebars}

It was shown in [20] that stress gradually transfers from UHPFRC to steel rebars in R-UHPFRC as the number of fatigue cycles increases. This is due to degradation of deformation modulus of UHPFRC. In order to verify this stress transfer, evolution of stress in the UHPFRC and steel rebars was investigated. As no direct deformation measurement on the steel rebars was performed, stress in steel rebars was calculated according to Eq. (3) using the modulus of elasticity and global deformation measurements obtained from LVDTs on the UFPFRC surface.

$\sigma_{s}=E_{s} \cdot \frac{\Delta \ell_{g}}{\ell_{b}}$

where $\sigma_{s}$ is the stress in steel rebar; $E_{s}$ the modulus of elasticity of steel rebar (= $205 \mathrm{GPa}) ; \Delta \ell_{g}$ global deformation; $\ell_{b}$ base length of 


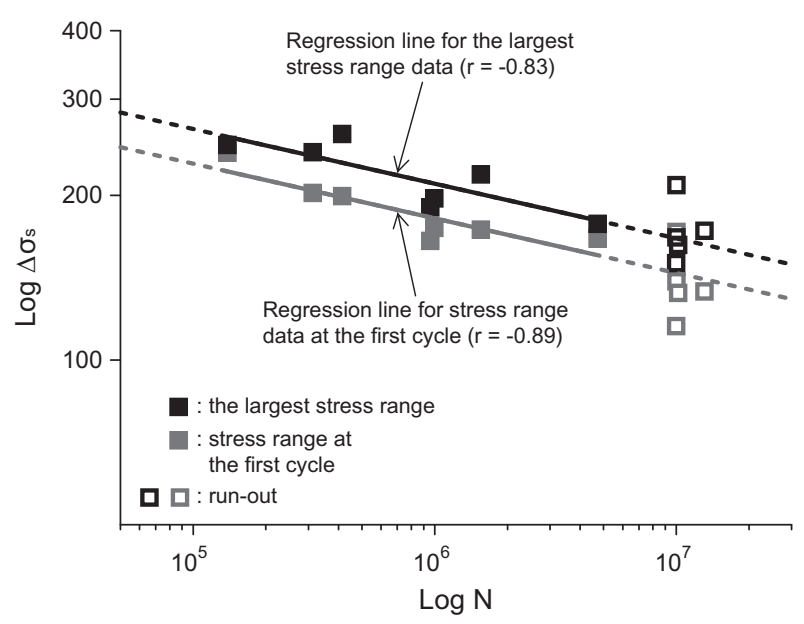

Fig. 7. $S-N$ diagram for stress range in steel rebars of R-UHPFRC.

LVDTs. Stress in UHPFRC $\sigma_{U}$ was then obtained by subtracting the force carried by steel rebars from applied force $F$ according to the following equation:

$\sigma_{U}=\frac{F-A_{s} \cdot \sigma_{s}}{A_{U}}$

Fig. 7 shows $S-N$ diagram for stress range in the steel rebars as calculated according to Eq. (3). Both the stress range at the first fatigue cycle and the largest stress range during a fatigue test are plotted. The initial fatigue test result was used to draw the $S-N$ diagram in case that more than one fatigue test was conducted to a specimen.

The stress range in the steel rebars of all R-UHPFRC specimens became the largest before the number of fatigue cycles reached $5 \times 10^{5}$. Accordingly, it is understood that stress range in the steel rebars of R-UHPFRC gradually grew larger as the number of fatigue cycles increased. Considering equilibrium of internal and external forces in the R-UHPFRC specimen, stress transfer from UHPFRC to steel rebars may be inferred. Fig. 8 shows the evolution of stress range in UHPFRC and steel rebar during Test 8-i and 10 using Eqs. (3) and (4), describing stress transfer from UHPFRC to steel rebars in R-UHPFRC.

Fatigue strength expressed as a linear relation between $\log \Delta \sigma_{s}$ and $\log N$ was determined by linear regression (without considering run-outs) for data of stress range at the first cycle and the largest stress range in the rebars with correlation coefficients of -0.89 and -0.83 respectively (Fig. 7 ):

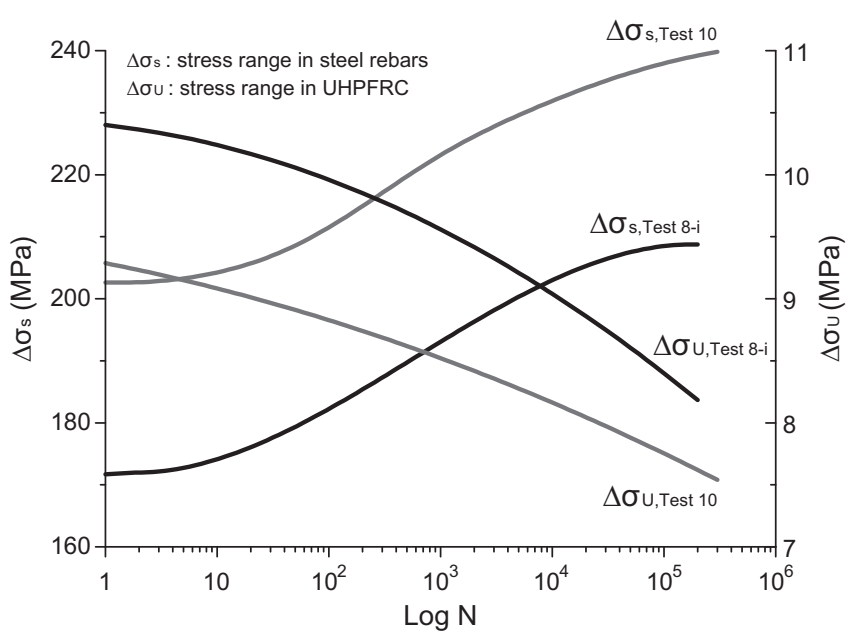

Fig. 8. Evolution of stress range in UHPFRC and steel rebars during Test 8-i and 10. $\log \Delta \sigma_{s}=-0.1 \log N+2.86$ (stress range at the first cycle)

$\log \Delta \sigma_{s}=-0.1 \log N+2.92$ (the largest stress range)

Comparing these fatigue strength equations, it is interpreted that the more fatigue stress cycles the R-UHPFRC specimen sustains, the smaller the stress transfer from UHPFRC to steel rebars. These findings support the fact that if the stress range in the steel rebars is small, R-UHPFRC specimen survives longer in the fatigue test because steel rebars determine the fatigue behaviour of R-UHPFRC except in the early stage of the fatigue test (as explained in Section 4.2).

\subsection{Fatigue deformation behaviour}

Tensile fatigue testing was conducted while imposing constant maximum and minimum forces and specimen deformation as a function of fatigue cycles was recorded. Similar deformation behaviour was observed from all R-UHPFRC specimens under tensile fatigue. The recorded global deformation of R-UHPFRC is discussed in terms of three regimes of characteristic behaviours using the example of the specimen behaviour of Test 5 .

\section{(1) Small deformation growth}

Global deformation of R-UHPFRC specimen grew only in the early stage of the fatigue test (up to about $5 \times 10^{5}$ cycles), and then remained approximately constant during the fatigue test until one
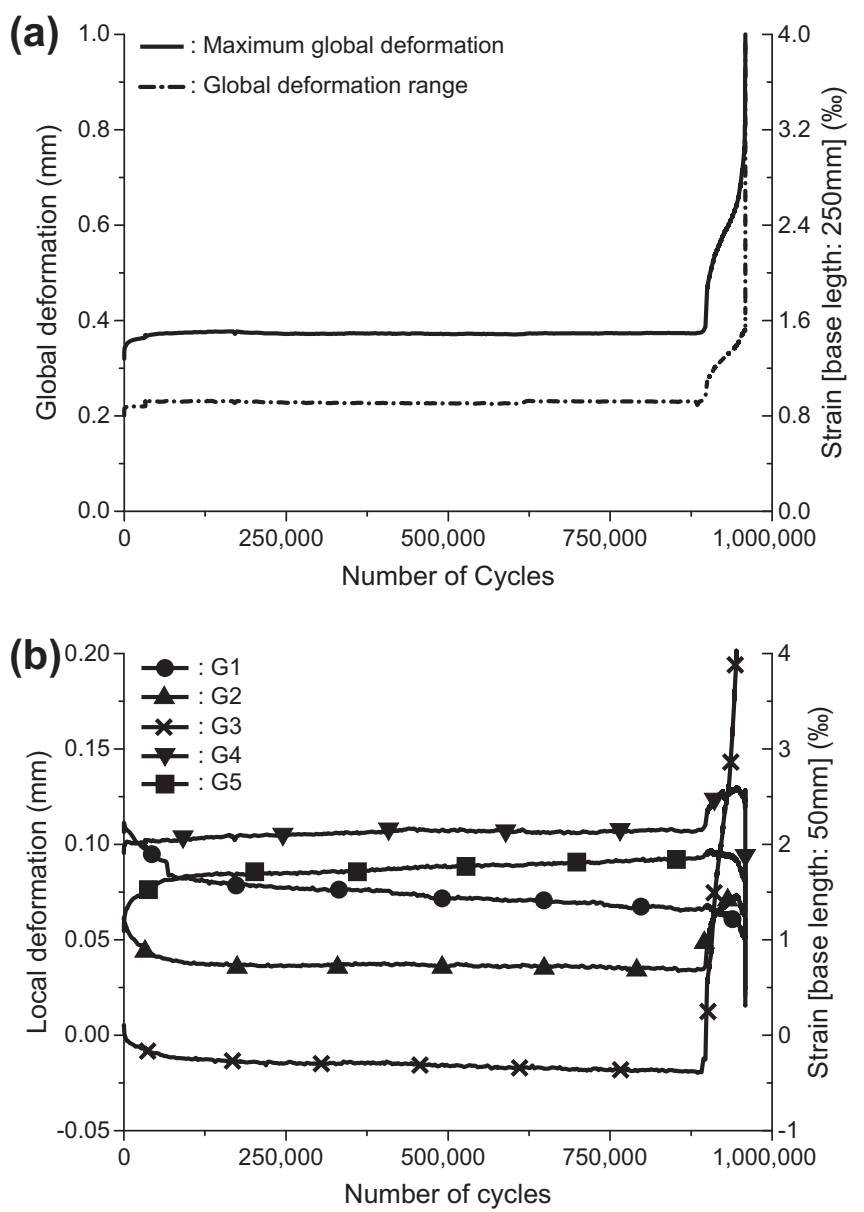

Fig. 9. Recorded deformation growth curves during Test 5 (a) maximum global deformation and global deformation range, and (b) local deformations over the specimen length. 


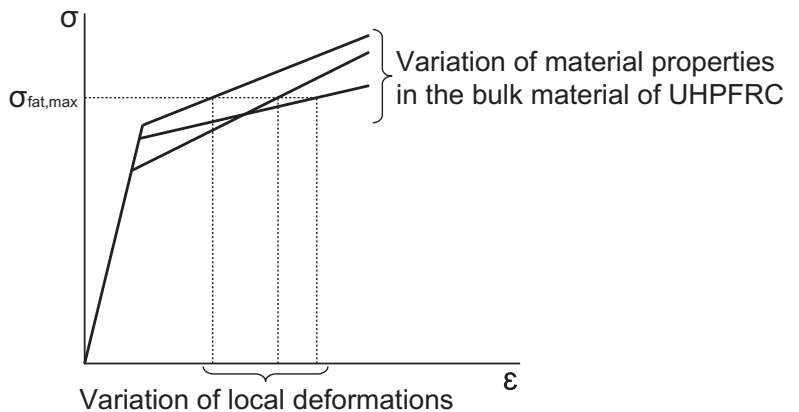

Fig. 10. Variation of local deformation of UHPFRC at given tensile fatigue stress.

of the steel rebars fractured (Fig. 9a). This is attributed to stress transfer from UHPFRC to steel rebars.

In the early stage of the fatigue test, UHPFRC mainly carried fatigue stress and deformation behaviour of R-UHPFRC was strongly influenced by UHPFRC whose deformation was observed to grow under tensile fatigue [19]. This is why global deformation of RUHPFRC increased in the early stage of the fatigue test. Then, fatigue stress gradually transferred to the steel rebars and steel rebars became main fatigue stress carrying element in R-UHPFRC. Consequently, deformation behaviour of R-UHPFRC was predominantly influenced by steel rebars and since steel rebars do not show any deformation growth under tensile fatigue, global deformation of the R-UHPFRC specimen was rather constant.

\section{(1) Variations in local deformation}

Variations in local deformations of R-UHPFRC were measured by $\mathrm{G} 1$ to $\mathrm{G} 5$ transducers (Fig. 9b). This may again be explained by stress transfer from UHPFRC to steel rebars.

As explained in the preceding paragraph, UHPFRC controlled the behaviour of R-UHPFRC in the early stage of the fatigue test. Under tensile fatigue stress, local deformation of UHPFRC varied which is explained by variation of material properties of UHPFRC in the hardening domain [19] (Fig. 10). This UHPFRC behaviour led to variations in local deformation of R-UHPFRC in the early stage of the fatigue test. After the main fatigue stress carrying component of R-UHPFRC transferred from UHPFRC to steel rebars, these variations in local deformation persisted because deformations induced in the UHPFRC at the early stage of the fatigue test remained constant.

\section{(3) Conservation of force bearing capacity of UHPFRC}

Although applied fatigue force is beyond the elastic limit strength of UHPFRC, local deformation measurements indicate that deformation did not localise in the UHPFRC. Besides, modulus of deformation of the UHPFRC part was calculated to be around $10 \mathrm{GPa}$ in average for all run-out specimens using the following equation:

$D_{U, f a t, i}=\frac{\sigma_{U, \max , i}-\sigma_{U, \min , i}}{\varepsilon_{\max , i}-\varepsilon_{\min , i}}$

where $D_{U f a t, i}$ is modulus of deformation of the UHPFRC part at $i$-th cycle; $\sigma_{U, \max (\min ), i}$ maximum (minimum) fatigue stress in the UHPFRC part at $i$-th cycle calculated using Eq. (4); $\varepsilon_{\max (\min ), i}$ global maximum (minimum) fatigue strain of R-UHPFRC at $i$-th cycle.

From this it follows that when combined with steel rebars, UHPFRC keeps its fatigue force bearing capacity although it is subjected to stress within the strain-hardening domain in the fatigue test.

\subsection{Fracture mechanism of R-UHPFRC under tensile fatigue}

By analysing fatigue fracture surfaces of R-UHPFRC specimens by visual observation, fracture mechanism of R-UHPFRC under tensile fatigue may be identified. In the following, fatigue fracture surfaces of UHPFRC and steel rebar are separately discussed.

Matrix spalling and pulverisation, smooth fracture surface area and rust-coloured powdery products are three distinct features observed on the fatigue fracture surface of the UHPFRC. These phenomena were already observed on the fatigue fracture surfaces of

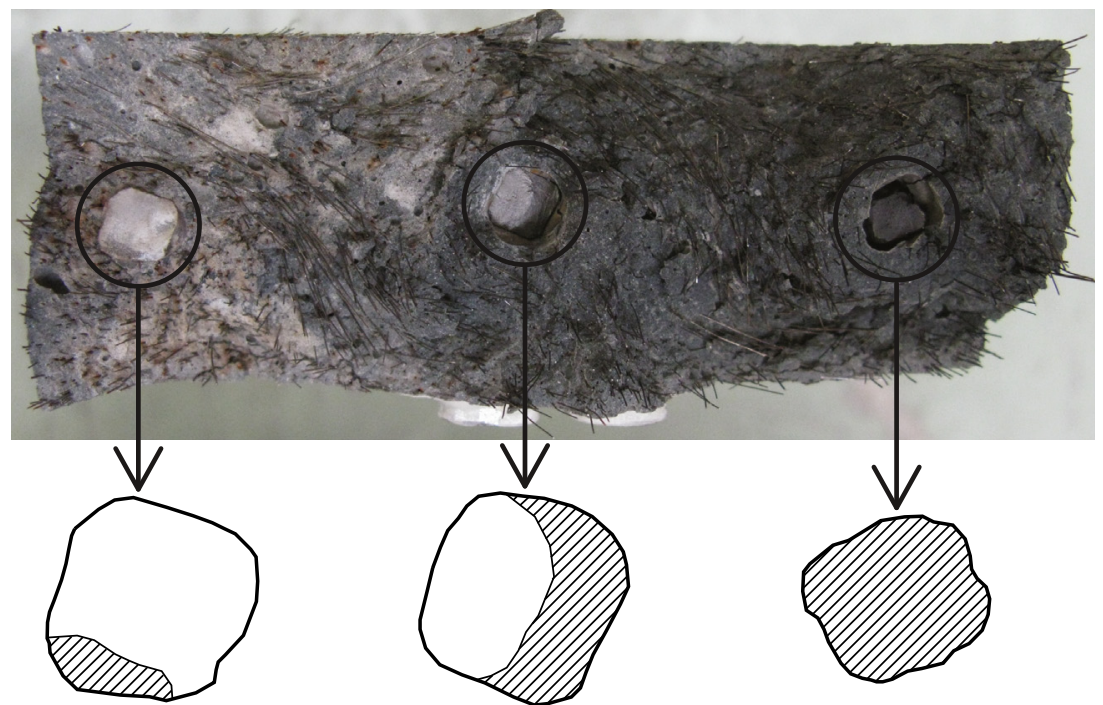

The first fracture (with the largest smooth The second fracture fracture surface)
The third fracture (with the largest rough fracture surface and reduced fracture surface area)

Fig. 11. Fatigue fracture surface of specimen of Test 5 and chronological order of fracture of the three steel rebars based on the characteristics of the fracture surfaces. 
monolithic UHPFRC specimen subjected to tensile fatigue stress in a previous study by the authors [19].

Fracture surface of steel rebar clearly indicated two distinct types of fracture surfaces, i.e., smooth and rough fracture surfaces. Smooth fracture surface indicates the well-known stable fatigue crack growth in steel. Rough fracture surface is brought about by rapid final fracture of the steel rebar when the applied fatigue stress reaches the ultimate resistance of the fatigue cracked rebar.

The characteristics of the fracture surfaces depict the chronological order of failure of the three steel rebars. The first fractured steel rebar is the one with the largest smooth fracture surface (Fig. 11). This is because fatigue stress imposed on each steel rebar was relatively small when all three rebars carried stress and fatigue crack grew slowly making fracture surface smooth. The steel rebar with the largest rough fracture surface is the one that fractured last under relatively high applied stress concentrating on the final rebar (Fig. 11). In addition, the last fractured steel rebar is also identified by a reduced fracture surface area due to necking (Fig. 11).

It is noted that deformation readings did not change even when fatigue crack growth occurred in steel rebars. Change in deformation readings was recorded only when one of the three steel rebars fractured.

\section{Conclusions}

The following conclusions can be drawn regarding the tensile fatigue behaviour of R-UHPFRC as obtained from uniaxial constant amplitude tensile fatigue tests:

(1) A constant amplitude fatigue endurance limit at 10 million cycles was determined to be at a solicitation level of $S=0.54$ for $S$ being the ratio between the maximum fatigue force and the ultimate strength of the R-UHPFRC specimen. Considering that at this force level, UHPFRC behaviour is in the strain-hardening domain, the steel rebars improve actually the fatigue force bearing capacity of UHPFRC by distributing the applied fatigue stress.

(2) The respective contribution of UHPFRC and steel rebars to the fatigue resistance of R-UHPFRC depends on the maximum fatigue force level and the stage of the fatigue test. Stress distribution and transfer between UHPFRC and steel rebars enhances the fatigue capacity of both material components.

(3) Fatigue deformation behaviour of R-UHPFRC depends on the stage of the fatigue test. In the early stage of the fatigue test, UHPFRC mainly determines the fatigue behaviour of $\mathrm{R}$ UHPFRC. In the middle and final stages of the fatigue test, steel rebars predominantly determine the fatigue behaviour of R-UHPFRC.

(4) Examination of the fatigue fracture surfaces of steel rebars revealed typical fatigue crack growth and final fracture surface. The chronological order of the fatigue failure of the three steel rebars was identified from the characteristics of the fracture surfaces.

\section{References}

[1] Wuest J, Denarié E, Brühwiler E. Measurement and modelling of fibre distribution and orientation in UHPFRC. In: Reinhardt HW, Naaman AE, editors. Proceedings of fifth international RILEM workshop on high performance fiber reinforced cement, Composites (HPFRCC5); 2007.

[2] Brühwiler E, Denarié E. Rehabilitation and strengthening of concrete structures using Ultra-High Performance Fibre Reinforced Concrete. SEI 2013;23(4). in press.

[3] Jungwirth J, Muttoni A. Structural behavior of tension members in UHPC. In: Schmidt M, Fehling E, Geisenhanslüke C, editors. Proceedings of international symposium on ultra-high performance concrete, Kassel, Germany; September $13-15,2004$, p. $533-44$.

[4] Redaelli D, Muttoni A. Tensile behaviour of reinforced Ultra-High Performance Fiber Reinforced Concrete elements. In: Radić J, editor. Proceedings of fib symposium: concrete structures - stimulators of development, Dubrovnik, Croatia; May 20-23, 2007.

[5] Leutbecher T, Fehling E. Crack formation and tensile behaviour of UHPC reinforced with a combination of rebars and fibres. In: Fehling E, Schmidt M, Stürwald S, editors. Proceedings of the second international symposium on ultra-high performance concrete. Kassel; March 5-7, 2008, p. 497-04.

[6] Oesterlee C. Structural response of reinforced UHPFRC and RC composite members, Doctoral thesis No. 4848, Ecole Polytechnique Fédérale de Lausanne (EPFL), 2010 http://infoscience.epfl.ch/record/150553.

[7] Bache HH. Compact reinforced composite, United States Patent, Patent No. 4979992, Date of patent: December 25, 1990.

[8] Behloul M, Chanvillard G, Pimienta P. Fatigue flexural behavior of pre-cracked specimens of special UHPFRC. In: Russell HG, editor. Proceedings of seventh international symposium on the utilization of high-strength/high-performance concrete. ACI Symposium Publication 228; 2005, p.1253-68.

[9] Farhat FA, Nicolaides D, Kanellopoulos A, Karihaloo BL. High performance fibre-reinforced cementitious composite (CARDIFRC) - performance and application to retrofitting. Eng Fract Mech 2007;74:151-67.

[10] Lappa ES, René Braam C, Walraven JC. Flexural fatigue of high and ultra high strength fiber reinforced concrete. In: Fischer G, Li VC, editors. Proceedings of international RILEM workshop on high performance fiber reinforced cementitious composites in structural applications, Ann, Arbor; 2006, p. 509-18.

[11] Parant E, Rossi P, Boulay C. Fatigue behaviour of a multi-scale composite. Cem Concr Res 2007;37:264-69.

[12] Fitik B, Niedermeier R, Zilch K. Fatigue behaviour of ultra high performance concrete under cyclic stress reversal loading. In: Proceedings of the 11th annual international fib symposium - concrete: 21 st century superhero, 2009.

[13] Tilly GP. Fatigue of steel reinforcement bars in concrete: a review. Fatigue Eng Mater Struct 1979;2:251-68.

[14] Zheng H, Abel AA. Fatigue properties of reinforcing steel produced by TEMPCORE process. J Mater Civ Eng 1999;11(1999):158-65.

[15] Rocha M, Brühwiler E. Prediction of fatigue life of reinforced concrete bridges using fracture mechanics. In: Biondini F, Frangopol DM, editor. Proceedings of 6 th international conference on bridge maintenance. Safety and Management (IABMAS 2012), p. 3755-60.

[16] Schläfli M, Brühwiler E. Fatigue of existing reinforced concrete bridge deck slabs. Eng Struct 1998;20(11):991-98.

[17] Sadananda K, Vasudevan AK, Phan N. Analysis of endurance limits under very high cycle fatigue using a unified damage approach. Int J Fatigue 2007:29:2060-71.

[18] Makita T, Brühwiler E. Fatigue behaviour of bridge deck slab elements strengthened with reinforced UHPFRC. In: Biondini F, Frangopol DM, editors. Proceedings of 6th international conference on bridge maintenance. Safety and Management (IABMAS 2012), p. 1974-80.

[19] Makita T, Brühwiler E. Tensile fatigue behaviour of ultra-high performance fibre reinforced concrete (UHPFRC). Mater Struct 2013 submitted for publication.

[20] Herwig A. Reinforced concrete bridges under increased railway traffic loads fatigue behaviour and safety measures, Doctoral thesis No. 4010, Ecole Polytechnique Fédérale de Lausanne (EPFL), 2008 http://infoscience.epfl.ch/ record/114778 